then appear to 'release' the behaviour concerned; but it is not (at least always) the sole factor which will elicit the behaviour.

On the above view, releasers are considered to be specialized and secondary. The ability of birds to evolve releasing complexes is clearly of value to the species, and this modification of the concept in no way diminishes the importance of Lorenz's arguments on the nature and evolution of display patterns in birds, since it is agreed that a particular pattern is often the most important (though not necessarily the sole) factor eliciting a particular train of behaviour.

The robin's own mate apparently possesses all the main factors èliciting aggressive behaviour but is attacked extremely rarely and only mildly. This and other facts discussed in the paper cited show the complexity of the problem, which I have been unable to reconcile with any theory of behaviour. The partial separation of the behaviour into particular stimuli with particular responses suggests a mechanistic rather than a holistic interpretation; but the incompleteness of the separation shows a simple mechanistic interpretation to be inadequate.

Dartington Hall,

DAvin LACK.

Totnes, Devon.

Dec. 27.

${ }^{2}$ Lorenz, K., J. Orn., 83, 137-213, 289-413 (1938); Auk, 54, 245-273 (1937).

${ }^{2}$ Lack, D., Proc. Zool. Soc., A, 109, 200-216 (1939).

\section{Osmotic Properties of the Common Prawn}

IN a previous communication ${ }^{1}$ I referred to the homoiosmotic behaviour of Palcemonetes varians and its ability to maintain hypotonicity in normal sea water. Further experiments on the osmo-regulatory mechanism of some Crustacea have revealed that the common prawn, Leander serratus (Pennant), is also definitely hypotonic when in normal sea water.

The blood of this prawn when taken from sea water has an osmotic pressure equivalent to $2 \cdot 6-2 \cdot 9$ per cent sodium chloride, the difference between the external and internal media being round about 0.7 per cent. This osmotic pressure is more or less retained by the animals up to dilutions of about 2.5 per cent in the external medium; but in lower dilutions there is a steady decline. In laboratory experiments $0 \cdot 5-1 \cdot 0$ per cent was the lowest range of salinities at which the prawns could live; and an osmotic pressure equivalent to that of $1 \cdot 3-1 \cdot 6$ per cent sodium chloride would seem to be the minimum internal osmotic pressure compatible with life.

Compared with Palæmonetes, Leander has a higher osmotic pressure when in normal sea water, and the ability to maintain the osmotic pressure of the blood near the optimum is also much less developed in Leander, as may be seen from the accompanying graph. The difference between the highest and lowest values for the blood of Leander in different dilutions is nearly $\mathbf{1 . 5}$ per cent, while the corresponding difference for Palæmonetes is only 0.5 per cent.

Studies on the rate of change of osmotic pressure when prawns are put in dilute sea water have shown that the reduction of the internal osmotic pressure goes on steadily and slowly during the first 14-24 hours, but after the lowest value has been reached there is a slight rise. It is worthy of note that the

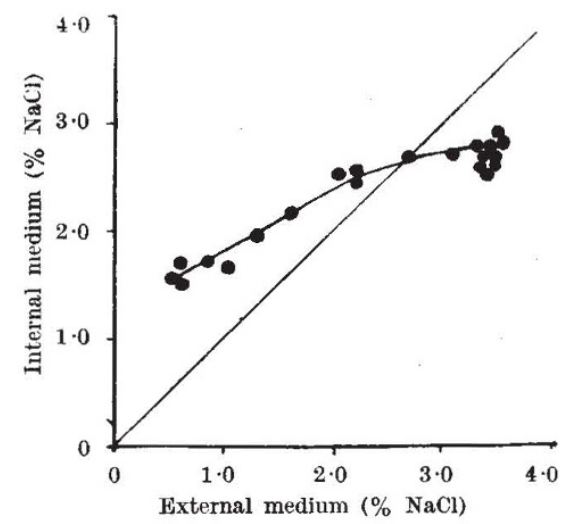

RELATION BETWEEN THE OSMOTIC PRES SURE OF BLOOD AND THE EXTERNAI. MEDIUM OF Leander serratus.

Values in per cent sodium chloride. Abscissæ, sea water ; ordinates, blood. Straight line indicates where points would fall if blood and medium were isotonic.

rate of change of osmotic pressure is different in individuals of different sizes. Young prawns 45-65 $\mathrm{mm}$. long respond to external osmotic changes more speedily than larger ones. The ability to live with a low osmotic pressure of the internal medium is also more pronounced in them than in full-grown individuals.

Leander serratus is a littoral species abundant in the southern parts of the North Sea and in the Mediterranean ${ }^{2}$. Though it is able to live in places where the salinity is slightly lower than that of the sea as observed at Plymouth, its habitat is essentially marine; but the osmotic behaviour of $L$. serratus is most unusual for a marine invertebrate. It is of great interest, since certain prawns like Leander longirostris M. Edw. are known to migrate many miles up rivers ${ }^{2}$ and many tropical species are known to be typical brackish-water and freshwater inhabitants ${ }^{3}$. If the osmotic properties of Leander serratus are shared by other species (and it seems very likely), it would explain their peculiar habits and distribution. The physiological evidence would seem to be in favour of considering this species of Leander as having taken secondarily to marine life, since its osmotic behaviour is so unlike that of most other marine invertebrates that have developed powers of osmo-regulation.

Marine Biological Laboratory,

N. Kesava Panikkar.

Plymouth.

Dec. 11.

${ }^{2}$ Panikkar, N. K., Nature, 144, 866 (1939).

${ }^{2}$ Gurney, R., Proc. Zool. Soc. London, 97 (1923).

${ }^{3}$ Kemp, S., Rec. Ind. Mus., 27, 287 (1925).

\section{Utilization of Nitrogen by Ophiobolus graminis}

THE survival period of the fungus Ophiobolus graminis, causing the 'take-all' disease of wheat, in infected wheat straw buried in the soil is increased by the application of nitrogen in such forms as calcium nitrate, ammonium nitrate, ammonium 